Vol 5. No 2. Agustus 2021

ISSN 2580-5029

\title{
Nematoda Parasit Pada Bunomys spp. di Pegunungan Mekongga, Sulawesi Tenggara
}

\author{
Muhammad Falikhul Musyaffa ${ }^{1}$, Kartika Dewi ${ }^{2 *}$, Mochammad Irfan Hadi ${ }^{3}$ \\ 1 Parasitologi dan Entomologi Kesehatan, Fakultas Kedokteran Hewan, IPB University, Bogor, \\ Indonesia \\ ${ }^{2}$ Bidang Zoologi, P2-Biologi LIPI, Cibinong, Indonesia \\ 3 Biologi, Fakultas Sains dan Teknologi, Universitas Islam Negeri Sunan Ampel, Surabaya, \\ Indonesia \\ *Email korespondensi: kartika_mzb@yahoo.co.id
}

\section{ABSTRACT}

Study on the nematode parasite species of Bunomys spp. from Mekongga Mountain, Southeast Sulawesi was conducted on deposited specimens in Museum Zoologicum Bogoriense, Zoology Division, Research Center of Biology-LIPI. Bunomys is endemic genus murine rodent in Sulawesi. This study aims to determine the types of nematodes in endemic Muridae rodent, the results of which can help the government in developing disease management plans. The nematodes identified in this study were Subulura andersoni (host: B. andrewsi), Syphacia rifaii (host: B. chrysocomus), Cyclodostomum purvisi (host: B. penitus), Heterakis spumosa (host: $B$. chrysocomus). Except for Sy. muris, all of the recorded nematodes have worldwide distribution. Morphology and taxonomy of nematodes will be discussed in this paper.

Keywords: nematodes, Bunomys, Mekongga Mountain, endemic rodent

\section{ABSTRAK}

Penelitian mengenai jenis-jenis nematoda pada Bunomys spp. dari Pegunungan Mekongga dilakukan pada spesimen yang disimpan di Museum Zoologicum Bogor, Bidang Zoologi, Pusat Penelitian Biologi LIPI. Bunomys adalah tikus endemik Sulawesi. Penelitian ini bertujuan untuk mengetahui jenis nematoda pada tikus endemik yang hasilnya dapat membantu pemerintah dalam menyusun rencana penanggulangan penyakit. Hasil identifikasi nematoda adalah Subulura andersoni (inang: B. andrewsi), Syphacia rifaii (inang: B. Chrysocomus), Cyclodostomum purvisi (inang: B. penitus), Heterakis spumosa (inang: B. chrysocomus). Semua nematoda yang diperoleh mempunyai daerah penyebaran yang luas di dunia kecuali Sy. muris.

Kata Kunci: nematoda, Bunomys, Pegunungan Mekongga, tikus endemik

\section{PENDAHULUAN}

Tikus merupakan hewan yang sering dijumpai hidup dan tinggal bersama di lingkungan manusia. Tikus sendiri mempunyai kemampuan adaptasi yang cepat dan besar pada lingkungannya, sehingga persebarannya sangat luas di dunia ini (Pisanu et al. 2007; Suyanto 2006). Luasnya 
persebaran dari tikus menjadikannya sebagai salah satu reservoir penyakit. Penyakit

Bunomys adalah salah satu genus tikus endemik di Sulawesi dan mempunyai habitat di daerah bukit berhutan, gunung dan lembah pegunungan (Musser 2014). Genus ini sampai saat ini mempunyai delapan jenis. Salah satu daerah yang dihuni tikus tersebut adalah Pegunungan Mekongga yang terletak di Sulawesi Tenggara. (Musser 2014; Grant et al. 2003).

Informasi mengenai cacing parasit pada tikus di Sulawesi sudah cukup banyak terungkap yang sebagian besar tulisan tersebut membahas mengenai jenis-jenis nematoda yang ada di Sulawesi beserta deskripsi jenis baru (Dewi 2011; Dewi et al. 2014; aHasegawa dan Syafrudin 1994; Purwaningsih dan Dewi 2007). Beberapa jenis nematoda yang pernah dilaporkan menginfeksi tikus seperti Bunomystrongylus abadii dan Bunomystrongylus miyagii yang dikoleksi dari tikus Bunomys spp. (Hasegawa dan Mangali, 1996), Hasanuddinia maxomyos dari tikus Maxomys musschenbroekii dan Eropeplus canus; Heligmonoides musseri dari M. musschenbroekii, E. canus, dan Margaretamys elegans (Hasegawa dan Syafruddin, 1994), Paraheligmonelloides eropeplios dari tikus E. canus; Paraheligmonelloides paruromyos dari dominator Paruromys; Odilia sulawesiensis dan Odilia moatensis dari tikus Rattus xanthurus; Odilia mamasaensis dan Odilia maxomyos dari tikus $M$. musschenbroekii (Hasegawa et al., 1999). Jenis baru nematoda yaitu Syphacia rifaii dari Bunomys spp. (Dewi dan Hasegawa 2010).

Masyarakat di daerah Sulawesi banyak mengkonsumsi tikus. Mereka memperjual belikan daging tikus di pasar tradisional (Suwarna dan Elita 2013). Kegiatan tersebut diduga berpotensi menjadi transmisi penyakit dari tikus kepada manusia yang disebabkan nematoda. Untuk itu penelitian mengenai nematoda tikus di daerah Sulawesi sangat menarik. Sehingga dilakukan penelitian untuk mengkonfirmasi tentang jenis Nematoda yang menginfeksi tikus Bunomys spp. Hasil dari penelitian ini diharapkan dapat mengungkap keragaman cacing parasit nematoda pada tikus dan membantu pemerintah dalam menyusun rencana penanggulangan penyakit yang disebabkan nematoda.

\section{METODE}

Identifikasi dilakukan pada spesimen nematoda yang tersimpan di koleksi basah Museum Zoologicum Bogoriense, P2 BiologiLIPI. Spesimen tersebut berasal dari Pegunungan Mekongga, Sulawesi Tenggara dan belum teridentifikasi.

Identifikasi dilakukan dengan merendam cacing dalam lacthopenol sampai terlihat transparan untuk kemudian diamati menggunakan mikroskop cahaya dan diukur karakter - karakternya menggunakan mikrometer. Untuk pengamatan SEM dilakukan hanya untuk Subulura andersoni. Sebelum diamati menggunakan SEM, cacaing fiksasi dengan glutaraldehyde, tannin acid 
kemudian didehidrasi dengan alkohol bertingkat dan dibekukan dengan tertbuthanol kemudian dikeringkan menggunan vaccum dryer.

Nematoda diidentifikasi melalui hasil pengukuran dan ciri-ciri yang didapat menggunakan kunci identifikasi Systema Helminthum (Yamaguti, 1961) dan jurnaljurnal ilmiah yang berkaitan (tercantum dalam daftar pustaka). Data ukuran dinyatakan dalam skala mikrometer $(\mu \mathrm{m})$, kecuali disebutkan dengan satuan lain.

\section{HASIL DAN PEMBAHASAN}

Berdasarkan hasil pemeriksaan nematoda parasit pada Bunomys spp. dari Pegunungan Mekongga didapatkan jenis nematoda sebagai berikut:

\section{Subulura andersoni (Cobbold, 1876)}

Class : Sercenentea

Ordo : Ascaridida

Famili : Subuluridae

Genus : Subulura

Species : Subulura andersoni

(Cobbold, 1876)

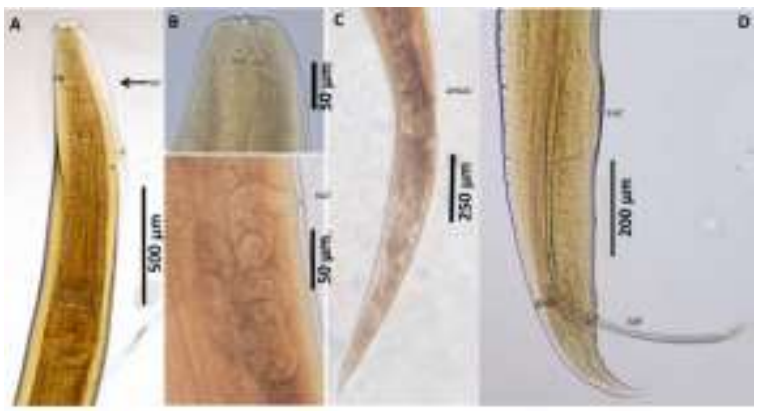

Gambar 1. Subulura andersoni. A. Bagain anterior, B. Ujung anterior, C. Posterior betina, D. Posterior jantan. Keterangan: nr: Nerve ring; ca: Caudal alae; vul: Vulva; suc: Sucker; gub: Gubernakulum; spi: Spicula
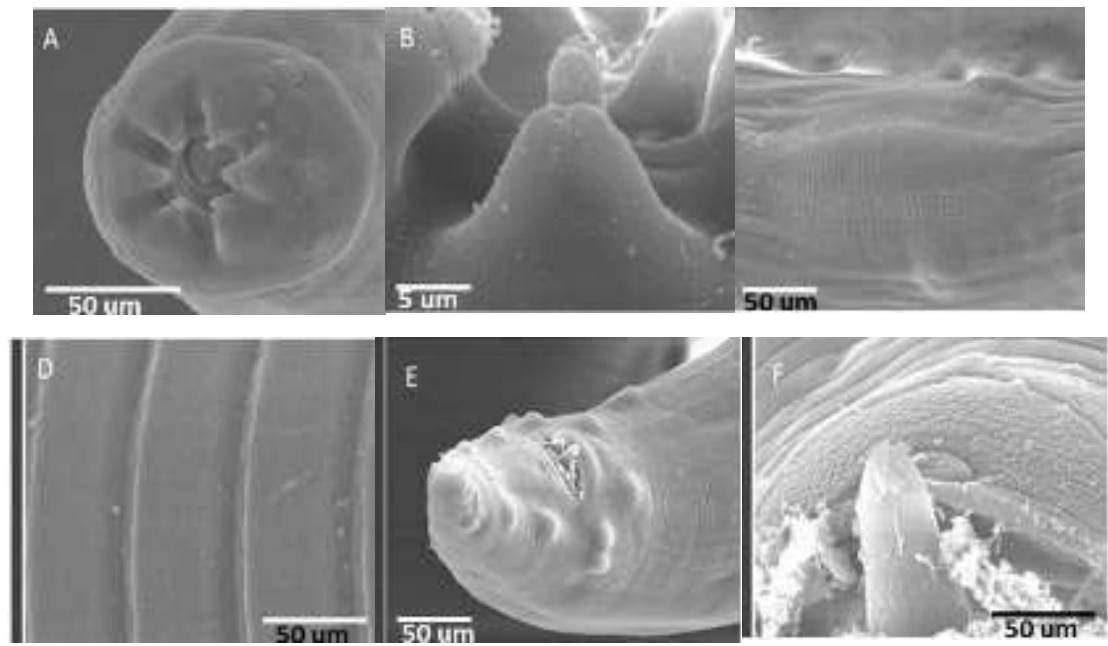

Gambar 2. Foto SEM Subulura andersoni. Keterangan: A. Mulut, B. Bibir, C. Sucker yang berbentuk bilah, D. Garis striasi pada bagian tengah badan, E. Ekor (ventral), F. Ujung spikula 
Inang: Bunomys andrewsi Deskripsi: Cacing ini mempunyai rongga mulut yang bibirnya tereduksi dan terbagi menjadi 6 bagian. Kepalanya berbentuk heksagonal dan memiliki satu pasang amphid dan dua pasang papilla di bagian bibirnya. Tubuhnya ramping dengan bagian posterior melengkung kearah ventral. Esophagus tersusun oleh pharing, copus dan bulbus. Mempunyai sayap leher (cervical alae) di bagian samping mulai dari akhir pharing sampai bagian atas bulbus.

Jantan (n=3): Panjang total tubuh 11,13 (10,37-12,27) mm, lebar 353 (299380). Jarak kedua amphid 83 (Gambar 4.2, $\mathrm{n}=1$; SEM) panjang pharing 39 (30-50); dan lebarnya 47 (40-53), panjang corpus 1,13 (1,06-1,40) mm dan lebarnya 154 (120-192), panjang bulbus 190 (170-200) dan lebarnya 186.6 (180-200). Panjang total esophagus 1362 (1266-1450). Jarak cincin saraf dan lubang eksketori dari ujung kepala berturut turut 287 (230-270) dan 380-430 (n=2). Panjang spikula $1,03 \quad(0,95-1,20) \mathrm{mm}$, panjang gubernakulum 100-150 (n=2), panjang ekor 238 (230-244). Jarak antara kloaka sucker dengan ujung ekor 680-720. Jumlah caudal papilla delapan pasang dan satu buah yang tidak berpasangan.

Betina ( $\mathbf{n = 3})$ : Panjang total tubuh 16,65 (15,95-17,42) mm, lebar 391 (305510). Panjang total esophagus 1577 (13731675) Panjang pharing 34 (25-50), lebarnya 44 (25-69), panjang corpus 1,28 (1,16-1,37) mm dan lebarnya 156 (125-200), panjang bulbus 222 (191-250) dan lebarnya 234 (225-250). Jarak cincin saraf, lubang ekskretori dan vulva dari ujung kepala berturut-turut 269 (268-270), 405 (n=2), vulva 5,69 $(5,59-6,12) \mathrm{mm}$. Panjang ekor $0,95 \quad(0,75-1,12) \mathrm{mm}$. Ujung posterior meruncing

\section{Syphacia rifaii Dewi \& Hasegawa, 2010}

$\begin{array}{ll}\text { Class } & \text { : Sercenentea } \\ \text { Ordo } & \text { : Oxyurida } \\ \text { Famili } & \text { : Oxyuridae } \\ \text { Genus } & \text { : Syphacia } \\ \text { Species } & \text { : Syphacia rifaii (Dewi dan } \\ & \text { Hasegawa, 2010) }\end{array}$
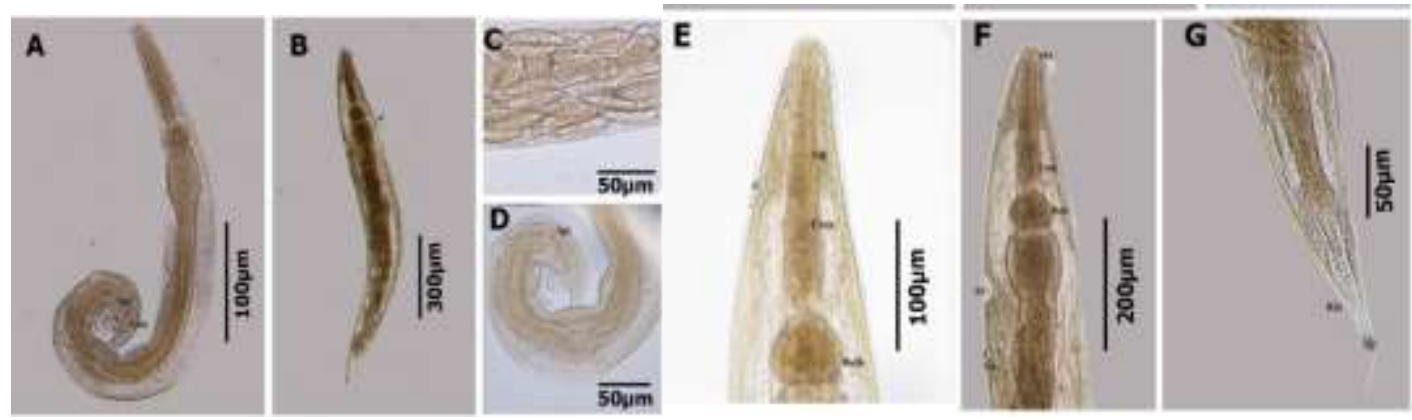

Gambar 3. Syphacia rifaii. A. Cacing jantan, B. Cacing betina, C. Telur di dalam uterus, D. Posterior jantan, E. Anterior, F. Anterior betina dengan nerve ring dan vulva, G. Posterior betina.

Keterangan: $\mathbf{a}=$ cacing jantan, $\mathbf{b}=$ cacing betina, $\mathbf{c}=$ telur, $\mathbf{d}=$ ekor cacing jantan, $\mathbf{e}=$ esophagus, $\mathbf{f}=$ jarak EP dari ujung mulut dan $\mathbf{g = e k o r}$ cacing beetina (pha=pharing, Bulb=bulbus, Corp=corpus, $\mathrm{NK}=$ nerve ring, $\mathrm{Klo}=$ kloaka, $\mathrm{EP}=$ ekskretori pore, $\mathrm{Spi}=$ spikula, Gub=gubernakulum)

Inang: Bunomys chrysocomus 
Deskripsi : Biasa disebut cacing peniti karena berukuran kecil. Rongga mulut dikelilingi oleh tiga buah bibir; satu buah bibir dorsal dan dua buah bibir subventral. Pada bibir dorsal terdapat sepasang amphid sedangakan pada bibir subventral terdapat masing-masing satu buah amphid dan satu papilla. Esophagus mempunyai bulbus yang terdiri dari pharing, corpus, istmus yang pendek dan berakhir pada bulbus.

Jantan (n=3) : Panjang total tubuh 869 (736-964), lebar 80 (72-91). Panjang total esophagus termasuk pharing, corpus dan bulbus 199.1 (185-215), Panjang pharing 10.8 (10-12) dan lebarnya 14 (12.5-15); panjang corpus 150 (140-165) dan lebarnya 23 (17-30), panjang bulbus 38 (42-37) dan lebarnya 40 (35-45). Jarak cincin saraf dan lubang eksretori dari ujung kepala 83 (63107) dan 361 (317-388). Panjang spikula 65 (62-67), panjang gubernakulum $25(17,-32$,) dan panjang ekor 39 (32,5-49). Bagian posterior melengkung ke arah ventral. Mempunyai 3 buah mamelon pada bagian ventral tubuh dengan panjang mamelon 41 (33-56), 41 (37-43), dan 34 (29-38). Terdapat tiga pasang papilla; dua pasang papilla dekat dengan kloaka dan satu pasang menonjol posterolateral..

Betina (n=3) : Panjang total tubuh 1.45 (1.32-1.65) mm, lebar 226 (150-230). Panjang total esophagus termasuk pharing, corpus dan bulbus 248.3 (238-264.5), Panjang pharing $17.5(\mathrm{n}=3)$ dan lebar pharing 19 (17,5-20); panjang corpus 187 (175-192) dan lebarnya 33 (30-37); panjang bulbus 43
(25-55); dan lebarnya 57 (50-65). Jarak cincin saraf, lubang eksretori dan vulva dari ujung kepala berturut-turut 85 (74-109), 397 (370-420) dan 500 (470-530). Vulva terletak dibagian anterior. Panjang ekor 245 (240-250). Ujung posterior meruncing. Bentuk telur tidak simetris.

3. Cyclodostomum purvisi Adams, 1973

$\begin{array}{ll}\text { Class } & : \text { Sercenetea } \\ \text { Ordo } & : \text { Strongyloidea } \\ \text { Famili } & : \text { Chabertiidae } \\ \text { Genus } & : \text { Cyclodostomum } \\ \text { Species } & : \text { Cyclodostomum } \\ & \text { purvisi (Adams, } \\ & 1973)\end{array}$

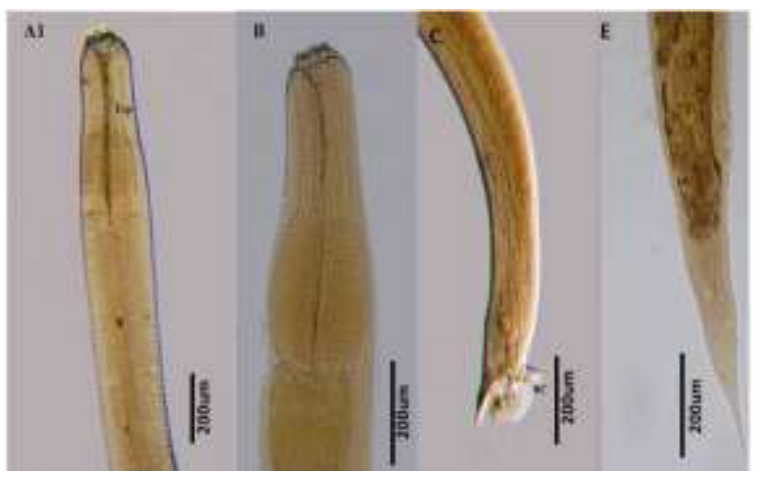

Gambar 4. Cyclodostomum purvisi.A, B. Bagian anterior, C. Posterior jantan, D. Posterior betina

\section{Inang: Bunomys penitus}

Deskripsi: Cacing ini mempunyai bukal kapsul pendek, mempunyai gigi berjumlah 16 yang runcing. Tidak mempunyai bibir pada mulutnya, meliliki satu pasang amphid dan dua pasang papilla. Ujung kepala miring kearah dorsal.

Jantan (n=3) : Panjang total tubuh 5,21 (4,78-5,88) mm, lebar 145 (125-174). Lebar 
kepala $\quad 70-100 \quad(n=2) . \quad$ Panjang total esophagus 484 (402-550) dan lebarnya 192 (175-200). Jarak cincin saraf dan lubang eksretori dari ujung kepala 172-210 (n=2) dan 301,5-325 (n=2), panjang spikula 610 (530-701), panjang gubernakulum 47,5 (4250). Mempunyai bursa kapulatrik.

Betina (n=3): Panjang total tubuh 7,33 (6,49-8,22) mm, lebar 370 (360-380). Lebar kepala 88 (80-100). Panjang esophagus 552 (500-580) dan lebarnya 168 (160-180). Jarak cincin saraf dan lubang eksretori dari ujung kepala berturut-turut 203 (150-290) dan 300-380 (n=2), jarak vulva 563 (550580) dari ujung posterior. Letak vulva pada bagian posterior, dekat dengan anus. Panjang ekor 166 (120-200).

4. Heterakis spumosa Schneider, 1866

$\begin{array}{ll}\text { Class } & \text { : Sercenentea } \\ \text { Ordo } & \text { : Ascaridida } \\ \text { Famili } & \text { : Heterakidae } \\ \text { Genus } & \text { : Heterakis } \\ \text { Species } & : \text { H. spumosa }\end{array}$

(Schneider, 1866)

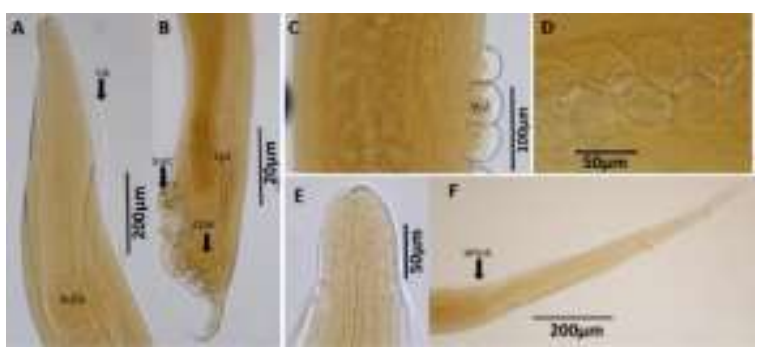

Gambar 5. Keterangan: A. Anterior jantan , B. Posterior jantan, C. Bagian vulva, D. Telur, E. Mulut, F. Posterior betina (keterangan: spi=spikula; ca=caudal alae; suc=sucker, cpa=caudal papilla dan vul=vulva)

\section{Inang: Bunomys chrysocomus}

Deskripsi : Mempunyai mulut yang dikelilingi tiga buah bibir; bibir dorsal dan dua buah bibir subventral. Pada bibir dorsal terdapat sepasang amphis sedangakan pada bibir subventral terdapat masing-masing satu buah amphid dan satu papilla. Terdapat lateral alae, esopaghus terdiri dari pharing yang pendek corpus, bulbus esophagus.

Jantan (n=1): Panjang total tubuh 4,47 $\mathrm{mm}$, lebar 255. Panjang pharing 72.5 dan lebarnya 25 Panjang corpus 551 dan lebarnya 63. Panjang bulbus 132 dan lebarnya 122. Jarak cincin saraf dan lubang eksketori dari ujung kepala 136 dan 277,5. Spikula dua buah, sama bentuk dan sama panjang dengan panjang 236. Tidak mempunyai gubernakulum. Panjang ekor 131. Sayap pada bagian posterior berkembang baik disokong oleh 6-15 pasang papilla bertakik. Terdapat anal sucker yang berbentuk bulat.

Betina (n=1): Panjang total tubuh 8,4 $\mathrm{mm}$, lebar 226. Panjang pharing 72,5 dan lebarnya 27,5; panjang corpus 671 dan lebarnya 75; panjang bulbus 150 dan lebarnya 150. Jarak cincin saraf dan lubang eksketori dari ujung kepala beturut turut 268 dan 337,5. Vulva terletak hampir ditengah badan Jarak vulva ke posterior 4,0 $\mathrm{mm}$. Panjang ekor 729. Ujung posterior meruncing dan bertakik. Telur mempunyai dinding yang tebal. Panjang telur $61(\mathrm{n}=1)$ dan lebar 38 $(n=1)$.

Pada penelitian ini jenis-jenis cacing yang ditemukan merupakan jenis yang umum dijumpai pada tikus, seperti $S$. andersoni, $H$ 
spumosa, dan C. purvisi, sedangkan Sy. rifaii merupakan nematoda yang hanya dijumpai pada genus Bunomys spp. (Dewi dan Hasegawa 2010). Untuk $S$. andersoni mempunyai catatan inang yang diinfeksi selain B. chrysocomus, B. andrewsi, dan $B$. penitus antara lain Bunomys prolatus, Rattus xanthurus, Mus elegans dan Rattus marmoxurus. Sebelumnya cacing ini pernah ditemukan pada B. penitus, Rattus tanezumi, Mus bartelsii, Rattus hoffmanni, Rattus lugens, Rattus tiomanicus yang berasal dari daerahdaerah Cibodas, Pangandaran, P. Siberut, Lampung, Sipirok-Sumatra Utara, Kendari, Dumoga Bone, Lore Lindu (Dewi et al. 2018).

Subulura spp. memerlukan inang antara dalam siklus hidupnya yang berupa jenis-jenis serangga. Infeksi pada tubuh inang terjadi secara oral, melalui larva infektif yang terkandung dalam tubuh inang antara. Vertebrata yang makan inang antara yang mengandung larva infektif dapat menjadi inang akhir dari S.andersoni (Anderson 1992). Menurut Purwaningsih (2003), panjang cacing jantan dan betina $S$. andersoni terkecil yang pernah ditemukan di Indonesia adalah cacing yang menginfeksi $B$. penitus dari Kendari, untuk cacing jantan terkecil berukuran $11,284 \mathrm{~mm}$ sedangkan cacing betina berukuran 27,650 mm. Ukuran S. andersoni dalam penelitian ini masih dalam kisaran ukuran yang disajikan pada Dewi et al. (2018). Tahun 2012, laporan menyebutkan bahwa di Jepang telah terjadi outbreak pada burung buyuh yang dikarenakan terjadinya penurunan bobot akibat infeksi dari Subulura brumtii (Nagarajan et al. 2012). Kasus tersebut membuat anggota genus Subulura lainnya, tak terkecuali $S$. andersoni berpotensi untuk menginfeksi burung puyuh. Untuk saat ini, infeksi genus Subulura pada manusia belum pernah dilaporkan.

Syphacia rifaii merupakan cacing kecil yang mempunyai kutikula dengan garis-garis transversal. cacing ini mempunyai tipe esophagus oxyuroid. Dalam laporan sebelumnya, Sy. rifaii ini pernah ditemukan di daerah Sulawesi Tengah oleh Dewi dan Hasegawa (2010) pada B. chrysocomus yang juga telah mendiskripsikan panjang jantan $0,67(0,60-0,78) \mathrm{mm}$ dan betina $1,82(1,40-$ $2,19) \mathrm{mm}$. Sedangkan dalam penelitian ini panjang jantan $0,86(0,73-0,96) \mathrm{mm}$ dan betina $1,45(1,32-1,65) \mathrm{mm}$. Sehingga dapat dikatakan bahwa cacing pada penelitian ini tidak jauh berbeda ukurannya dengan penelitian sebelumnya. Genus Syphacia berpotensi zoonosis karena terdapat laporan bahwa Syphacia obvelata menginfeksi manusia dilaporkan di Filipina (Riley 1919). Laporan lainnya diungkapkan oleh Mahmoud et al. (2009), bahwa terdapat 25 kasus infeksi Syphacia pada manusia di Mesir.

Cyclodonstomum purvisi merupakan sinonim dari Ancistronema coronatum. Cacing ini mempunyai inang tikus yang berasal dari genus yang bervariasi, seperti Rattus, Bandicota, Berylmys, Leopoldamys, Maxomys, Niviventer, dan Sundamys yang persebarannya mulai dari India sampai Autralia (aHasegawa dan Syafruddin 1994). 
Dalam penelitian yang dilakukan oleh aHasegawa dan Syafruddin (1994), cacing $C$. purvisi yang ditemukan di Sulawesi Utara dideskripsikan mempunyai ukuran panjang total tubuh jantan 4,4-8,8 $\mathrm{mm}$ dan betina 5,7-12,2 mm. Lebar cacing jantan 293-384 dan betina 280-576. Sedangkan dalam penilitian ini didapatkan hasil pengukuran panjang total jantan $5.2 \mathrm{~mm}$ dan betina 7,3 mm. Lebar jantan 125-174 $\mu \mathrm{m}$, dan betina $370 \mu \mathrm{m}$. Dari pengukuran ini dapat diketahui bahwa C. purvisi ini ukurannya tidak jauh berbeda dari hasil penelitian sebelumnya. Sampai saat ini, cacing jenis ini belum pernah dilaporkan dapat menginfeksi manusia, tetapi hanya meinfeksi tikus.

Heterakis spumosa merupakan sinonim dari Ganguleterakis spumosa (Raina dalam Purwaningsih dan Dewi 2007). H. spumosa mempunyai persebaran yang luas di dunia. Di Indonesia, cacing ini pernah ditemukan menginfeksi B. chrysocomus, B. prolatus, Rattus tiomanicus, R. tanezumi, R. hoffmanni, R. marmosurus dan $R$. xanthurus (Purwaningsih dan Dewi 2007). Dari daerah Lampung cacing ini pernah ditemukan pada R. tiomanicus (Suyanto et al. 1984) dan pada Rattus lugens dari P. Siberut (Purwaningsih dan Saim 1999). Dalam laporan sebelumnya, perbandingan cacing jantan dan betina mendekati 1:1 baik secara individu maupun secara keseluruhan (Purwaningsih dan Dewi 2007). Cacing jenis ini pernah juga dideskripsikan dari inang Rattus norvegicus dari Rio de Janeiro, Parcona, dan Buenos Aires oleh Robles et al. (2008). Menurut hasil penelitian tersebut $H$. spumosa yang ditemukan mempunyai panjang total cacing jantan 5,1-7,28 mm dan betinanya 7,5 - 10,2 $\mathrm{mm}$. Sedangkan dalam penelitian ini cacing jantan berukuran $4,47 \mathrm{~mm}$ dan betina berukuran 8,4 mm. Jika di bandingkan maka H. spumosa yang dideskripsikan oleh Robles ukuran $H$. spumosa dalam penelitian ini tidak jauh berbeda. Banyak laporan menyebutkan bahwa cacing ini dan anggota dari genusnya menginfeksi tikus, mencit, dan unggas. Tetapi belum ada loparan tentang infeksi cacing ini pada manusia.

\section{KESIMPULAN}

Hasil identifikasi spesimen nematoda pada Bunomys spp. dari Mekongga, Sulawesi Tenggara adalah Subulura andersoni, Syphacia rifaii, Cyclodonstomum purvisi,dan Heterakis spumosa. Cacing Sy. rifaii memiliki potensi untuk meinfeksi manusia.

\section{UCAPAN TERIMA KASIH}

Penulis mengucapkan terimakasih kepada tim proyek ICBG Mekongga, terutama kepada A.T. Hitch (University of California, Davis) and A.S. Achmadi (Bidang Zoologi, P2 Biologi-LIPI) karena diperbolehkan untuk membedah tikus yang digunakan untuk penelitian ini. Kepada K. Rowe (Victoria Museum, Australia) dan A.S. Achmadi yang telah mengidentifikasi tikus. Kami juga mengucapkan terimakasih kepada Y. Apriyanti yang telah menyiapkan materi untuk di SEM. Pengamatan SEM dibiayai oleh Proyek DIPA “Fauna Jawa” tahun 2018. 


\section{DAFTAR PUSTAKA}

Anderson, RC. 1992. Nematode Parasites of Vertebrata : Their Development and Transmission. CABI Publishing: Canada.

Anderson, RC. 2000. Nematode Parasites of Vertebrata 2nd Editon: Their Development and Transmission. CABI Publishing: Canada.

Dewi, K. 2007. Nematoda: Morfologi dan Siklus Hidupnya. Fauna Indonesia. 1, 2.

Dewi, K. and Hasegawa, H. 2010. A New Syphacia Species (Nematoda: Oxyuridae) Collected From Bunomys Spp. (Rodentia: Muridae) In Central Sulawesi, Indonesia. The Journal of Parasitology. 96(1): 125-127.

Dewi, K., Hasegawa, H. and Asakawa, M. 2018. Redescription of Subulura (Murisubulura) andersoni (Cobbold, 1876) (Nematoda: Subuluridae) from Bunomys spp. (Rodentia: Muridae) of Sulawesi, Indonesia, with special reference to $S$. (M.) suzukii and other related species in the adjacent areas. Journal Veterinary Medical Science. 80(10): 1639-1645.

Dewi, K. 2011. Nematoda Parasiti Pada Tikus di Desa Pakuli, Kec. Gumbara, Kab. Donggala, Sulawesi Tengah. Jurnal Ekologi Kesehatan. 10(1): 38-43.

Dewi, K., Hasegawa, H., and Asakawa, M. 2014. Description of Two New Species of Syphacia (Nematoda: Oxyuridae) Collected from Eropeplus canus (Rodentia: Muridae), an Endemic Rat of Sulawesi, Indonesia, with proposal of new subgenera. Raffles Bulletin of Zoology. 62: 647-654.

Grant, RS., Lyn, AH., Charles, JK. and Dave, MS. 2003. Rat, Mice and People: Rodent Biology and Management. ACIAR: Canberra.

Hasegawa, H. and Mangali, A. 1996. Two new nematode species of Bunomystrongylus n. gen. (Trichostrongylina: Heligmonellidae) collected from Bunomys spp. (Rodentia: Muridae) of Sulawesi, Indonesia. J Parasitol. 82(6): 998-1004.

Hasegawa, H., Miyata, A., and Syafruddin. 1999. Six new nematodes of the Heligmonellidae (Trichostrongylina) collected from endemic murines of Sulawesi, Indonesia. J Parasitol. 85(3): 513-524.

Hasegawa, H. and Syafruddina. 1994. Clycodontomum purvisi (syn. Ancistronema coronatum) (Nematoda: Strongyloidea: Chabertiidae) from Rats of Kalimantan and Sulawesi, Indonesia. The Journal of Parasitology American Society of Parasitologist. 80(4): 657659.

Hasegawa, H. and Syafruddin ${ }^{b} .1994$. Hasanuddinia maxomyos n. gen., n. sp. and Heligmonoides musseri $\mathrm{n}$. sp. (Nematoda: Heligmonellidae) collected from endemic murines of Sulawesi, Indonesia. J Parasitol. 80(5): 781-788

Mahmoud, A.E., R.A.H. Attia, H.E.M. Eldeek, L.A. Baki and H.A. Oshaish. 2009. Oxyurid nematodes detected by colonscopy in patients with unexplained abdominal. Parasitologists United Journal. 2: 93-102.

Musser, GG. 2014. A Systematic Review of Sulawesi Bunomys (Muridae, Murinae) with the Description of Two New Species. Bulletin of The American Museum of The Natural History. 392(392): 1-313.

Nagarajan, K., Thyagarajan, D. and Raman, M. Winter 2012. Subulura brumpti infection - An outbreak in Japanese quails (Coturnix coturnix japonica). Vet Res Forum. 3(1): 67-69

Pisanu, B., Jerusalem, C., Huchery, C., Marmet, J. dan Chapuis, JL. 2007. Helminth fauna of the Siberian chipmunk, Tamias sibiricus Laxmann (Rodentia, Sciuridae) introduced in sub urban French forests. Parasitol Res. 100(6): 1375-1379. 
Purwaningsih, E. 2003. Variasi Morfologi dan Jenis Inang Subulura andersoni Cobbold, 1887 Di Indonesia dan Deskripsi Subulura spiroki n. sp. Berita Biologi. 6(4): 563- 567.

Purwaningsih, E. and Dewi, K. 2007. Nematoda Pada Tikus Suku Muridae dan Pola Infeksinya Di Taman Nasional Lore Lindu, Sulawesi Tengah. Berita Biologi. 8(6): 509-514.

Riley, W.A. 1919. A mouse oxyurid, Syphacia obvelata, as a parasite of man. Jounal of Parasitology 6: 89-93.

Robles, MR., Graciela, TN. and Isabel, EGV. 2008. New Morphological Details and First Records of Heterakis spumosa and Syphacia muris from Argentina. Comparative Parasitology. 75(1): 145146.

Saim, A. and Puwaningsih, E. 1999. Pola Kandungan Cacing Parasitik Pada Tikus Liar dari Pulau Siberut, Sumatera Barat. Majalah Parasitologi Indonesia. 12(12): 49-60.

Suwarna, B. and Elita, PD. 2013. Makananan Minahasa Ketika Tikus Mengalahkan Sapi. Di akses pada Januari 2018. <http://travel.kompas.com/read/2013 /12/19/0841079/Makanan.Minahasa. Ketika.Tikus.Mengalahkan.Sapi>.

Suyanto, A. 2006. Rodent di Jawa. LIPI. Bogor

Yamaguti, S. 1961. Sytema Helmintum Vol III: The Nematode of Vertebrates. Interscience Publishers: New York 